\title{
Derivation of Rate Equations for Equilibrium Limited Gas-Solid Reactions
}

\author{
Marcus Wenzel ${ }^{1}$ and Kai Sundmacher ${ }^{1,2}$ \\ ${ }^{1}$ Max Planck Institute for Dynamics of Complex Technical Systems, Sandtorstr. 1, 39106 Magdeburg, \\ Germany \\ ${ }^{2}$ Otto von Guericke-University Magdeburg, Universitätsplatz 2, 39106 Magdeburg, Germany
}

\section{Abstract}

In this work the differences between the formulation of reaction rate equations for equilibrium limited reactions in homogeneous and heterogeneous systems are investigated. A rigorous derivation for equilibrium limited gas-solid reactions is proposed based on the core ideas of homogeneous gas phase reactions. The resulting reaction rate expression allows for two distinct reaction rate mechanisms for the forward and reverse reaction direction and is, therefore, valid in both reaction directions. The thermodynamic consistency and the validity of the proposed reaction rate expression is shown using a simple reactor model. The results are compared to traditional reaction rate expressions and it is explained why they are not able to appropriately describe the true reaction behavior in some cases. The implications and use cases for process modeling are investigated and suggestions are proposed for solving numerical challenges associated with the proposed reaction rate equations.

Keywords: rate equation; gas-solid reaction; equilibrium; process modeling; thermodynamics; dynamic simulation

\section{Introduction}

Many homogeneous gas phase reactions are equilibrium limited. Starting from either side of chemical equilibrium, they proceed until the reaction rates of the forward and reverse reaction are equal, i.e. until chemical equilibrium is reached. Therefore, the theoretically achievable conversion is limited and there is always a certain amount of reactants present at chemical equilibrium. When modeling equilibrium limited reaction systems, this fact is recognized by using thermodynamically consistent reaction rate expressions. Reaction rate equations are commonly termed as thermodynamically consistent when they satisfy two conditions: (1) they are positive in the direction of decreasing Gibbs energy, (2) they vanish (i.e. $r=0$ ) at chemical equilibrium ${ }^{1}$. A general mathematical representation of an equilibrium limited reaction rate that is thermodynamically consistent is given by Marin and Yablonski ${ }^{2}$ :

$$
r=\frac{k_{+}\left(f\left(\mathbf{c}_{\mathbf{r}}\right)-\frac{f\left(\mathbf{c}_{\mathbf{p}}\right)}{K_{\text {eq }}}\right)}{W(\mathbf{k}, \mathbf{c})}=\frac{\text { kinetic constant } \times \text { driving force }}{\text { resistances }}
$$

Here, $r$ is the reaction rate, $k_{+}$the forward rate coefficient, $\mathbf{c}_{\mathbf{r}}$ the vector of reactant concentrations, $\mathbf{c}_{\mathbf{p}}$ the vector of product concentrations and $\mathbf{k}$ a vector of kinetic coefficients. The function $W$ is a resistance term that reflects the complexity of the chemical reaction. The kinetics of many equilibrium limited homogeneous gas phase reactions are described by a function of the form of Equation (1), which is derived from the difference between the forward and reverse reaction rate.

However, equilibrium limitation is often disregarded for modeling of heterogeneous gas-solid reactions. This is a valid approximation for gas-solid reactions that are essentially irreversible, i.e. where the chemical equilibrium is so far on the product side that the reverse reaction can be neglected (e.g. combustion reactions of solid matter). However, there are important gas-solid reactions with marked equilibrium limitations. To accurately model these systems equilibrium limitation must be accounted for in the reaction rate expressions. In the following, a few examples of important equilibrium limited gas-solid reactions are presented to motivate this work.

Steam-iron process The reactions of iron in its different oxidation states with the systems $\mathrm{H}_{2} / \mathrm{H}_{2} \mathrm{O}$ and $\mathrm{CO} / \mathrm{CO}_{2}$ have been studied extensively in the context of iron production from iron ore in blast furnaces through direct reduction ${ }^{3}$. Recently, the steam-iron process ${ }^{4}$ gained renewed interest in the context of clean hydrogen production for fuel cell applications ${ }^{5}$. In the steam-iron process iron oxide is first reduced with hydrogen (or generally syngas produced from coal gasification) and then the resulting iron is re-oxidized with water to produce high purity hydrogen according to the following (simplified) equations:

$$
\begin{aligned}
\mathrm{Fe}_{3} \mathrm{O}_{4}(\mathrm{~s})+4 \mathrm{H}_{2} & \rightleftharpoons 3 \mathrm{Fe}(\mathrm{s})+4 \mathrm{H}_{2} \mathrm{O} \\
3 \mathrm{Fe}(\mathrm{s})+4 \mathrm{H}_{2} \mathrm{O} & \rightleftharpoons \mathrm{Fe}_{3} \mathrm{O}_{4}(\mathrm{~s})+4 \mathrm{H}_{2}
\end{aligned}
$$


The phase equilibrium of iron and its oxides in $\mathrm{H}_{2} / \mathrm{H}_{2} \mathrm{O}$ gas mixtures is illustrated in the Baur-Glaessner diagram as depicted in Figure 1. $\mathrm{FeO}$ is not a stable oxidation state below $\approx 850 \mathrm{~K}$. It can be seen that distinct equilibrium limitations exist for the reactions between $\mathrm{H}_{2} / \mathrm{H}_{2} \mathrm{O}$ and iron and its oxides.

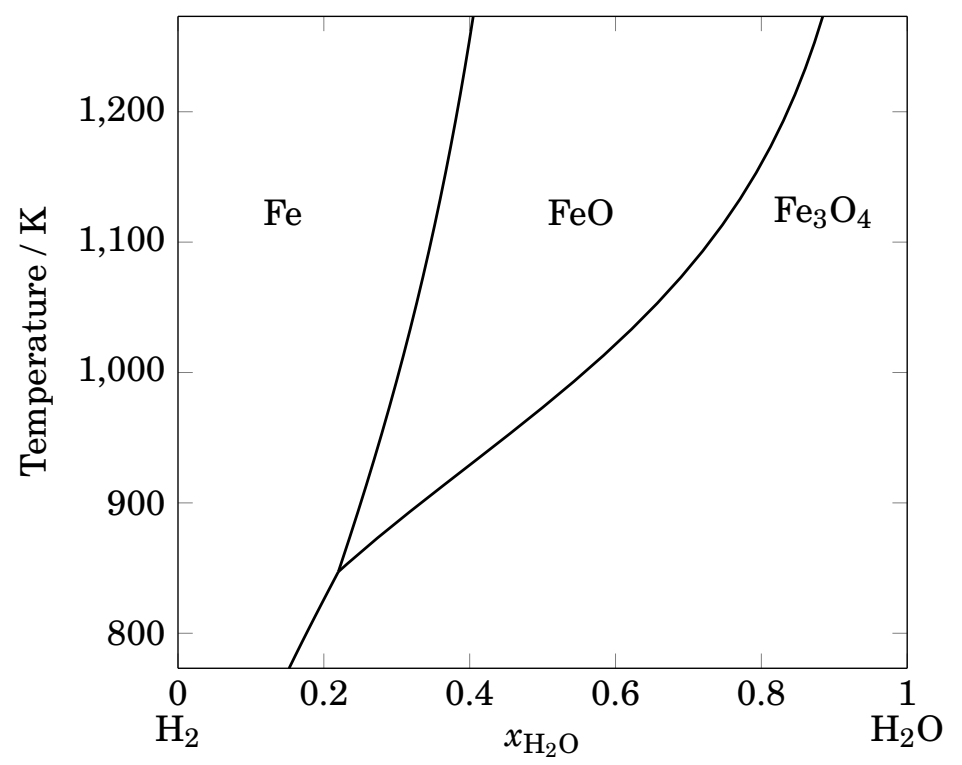

Figure 1: Baur-Glaessner diagram showing the equilibrium of different oxidation states of iron and the $\mathrm{H}_{2} / \mathrm{H}_{2} \mathrm{O}$ gas composition. Thermodynamic data taken from 6 [7].

The kinetics of the reduction and oxidation reaction of iron oxide at high temperature have been studied recently by Wang and Sohn and Yuan et al., respectively ${ }^{89}$. These publications are especially interesting because it was found that the reduction and oxidation reaction (Equations (2) and (3)) follow different reaction mechanisms.

Calcination of limestone Another important example is the calcination of limestone:

$$
\mathrm{CaCO}_{3}(\mathrm{~s}) \rightleftharpoons \mathrm{CaO}(\mathrm{s})+\mathrm{CO}_{2}
$$

The resulting quicklime $(\mathrm{CaO})$ has been used as mortar for buildings for thousands of years ${ }^{10}$. Figure 2 shows the equilibrium diagram for reaction (4). High temperature and low pressure favor the calcination reaction. The forward reaction (as expressed in Equation (4)) is favored in the operating region below the equilibrium line. The calcination of limestone is well studied as it is still of major industrial importance ${ }^{11}$. An investigation of the reverse reaction (carbonation of quicklime) was first published by Barker $\frac{12}{2}$. More recently, the carbonation of quicklime gained interest in the context of calcium looping for efficient $\mathrm{CO}_{2}$ capture and was studied by several research groups $13-16$. Therefore, kinetic information is available for both reaction directions. However, there is still no consensus on the rate limiting step for the calcination reaction ${ }^{[17}$ and the kinetic parameters estimated for the forward and reverse reaction direction vary significantly 18 . The shrinking core model is most widely used for the calcination reaction (Equation (4)) whereas the carbonation reaction (reverse of Equation (4)) is often described by a random pore model ${ }^{17}$.

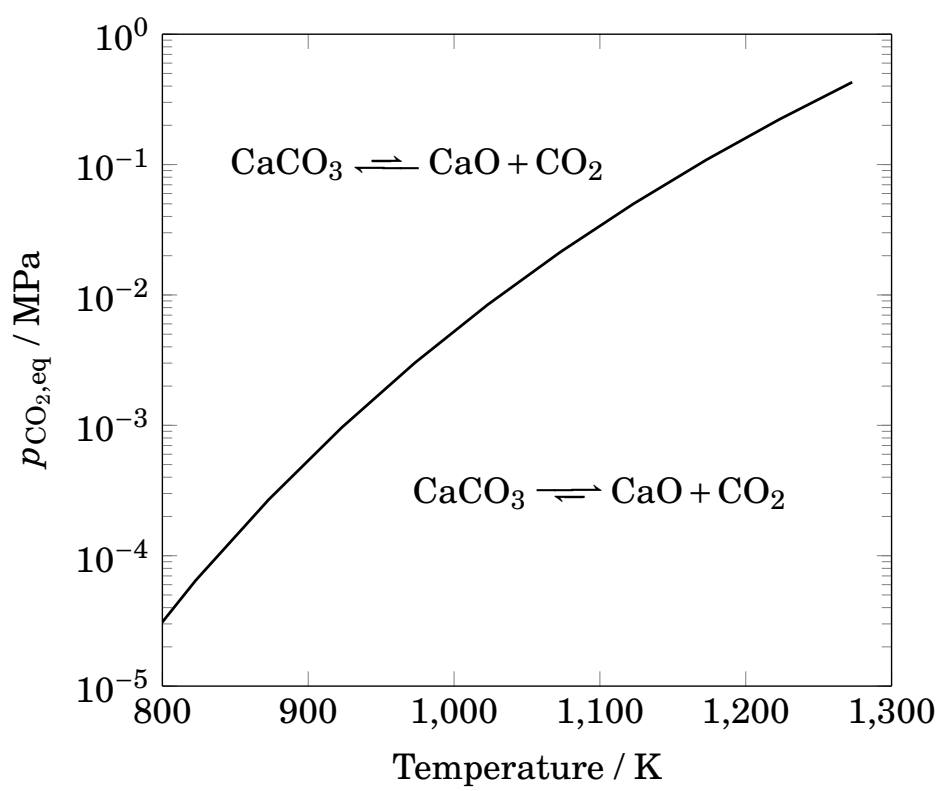

Figure 2: Chemical equilibrium for limestone calcination. At a temperature of $\approx 1170 \mathrm{~K}$ the equilibrium partial pressure of $\mathrm{CO}_{2}$ is equal to the atmospheric pressure. Equilibrium pressure correlation from ${ }^{19}$.

Boudouard reaction The CO disproportionation reaction (or Boudouard reaction) is given by the following reaction equation:

$$
2 \mathrm{CO} \rightleftharpoons \mathrm{C}(\mathrm{s})+\mathrm{CO}_{2}
$$

The Boudouard reaction is a well known side reaction in steam reforming of natural gas that causes catalyst deactivation by carbon formation (coking) $20-22$. A thermodynamically consistent reaction rate equation was proposed by Snoeck et al. ${ }^{20}$ which has been widely used for dynamic modeling of systems with carbon deposition $^{23-26}$. While the same reaction mechanism was derived for the forward and reverse direction of Equation (5) the estimated kinetic parameters for each direction varied significantly "meaning that the application of these equations is specific" 20 . Figure 3 shows the thermodynamic equilibrium between $\mathrm{CO}_{2}$ and CO. Carbon formation is favored at low temperature and high pressure.

Additional examples for equilibrium limited gas-solid reactions that are not further discussed here include:

$$
\begin{array}{ll}
\text { Coal gasification: } & \mathrm{C}(\mathrm{s})+\mathrm{H}_{2} \mathrm{O} \rightleftharpoons \mathrm{CO}+\mathrm{H}_{2} \\
\text { Bergius process: } & \mathrm{C}(\mathrm{s})+2 \mathrm{H}_{2} \rightleftharpoons \mathrm{CH}_{4}
\end{array}
$$




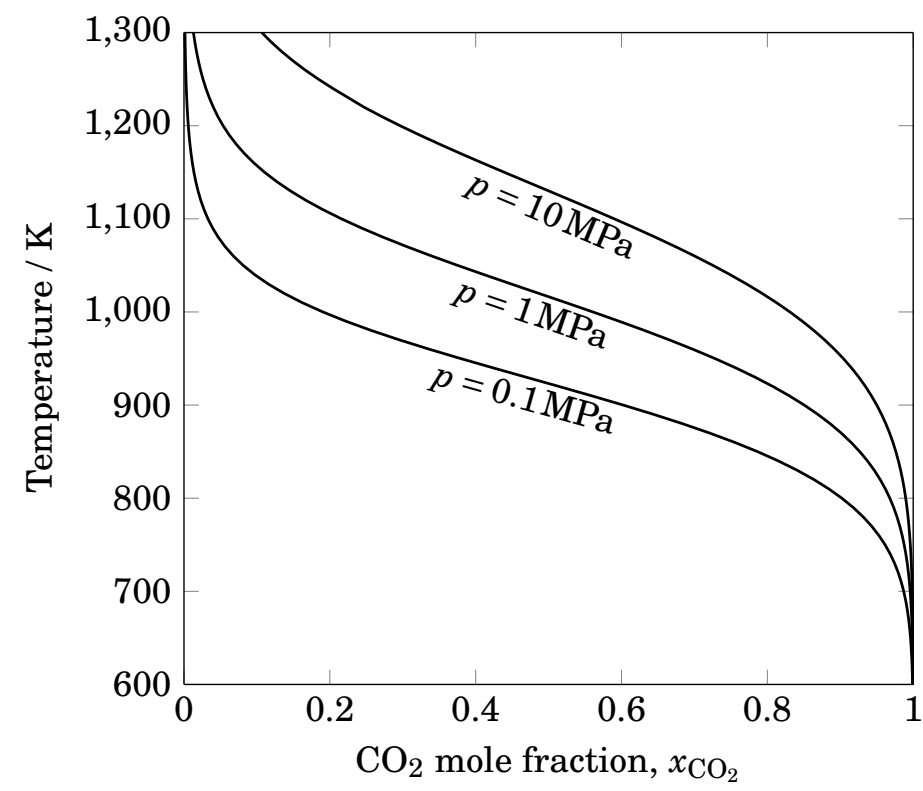

Figure 3: $\mathrm{CO}_{2}$ equilibrium lines in the Boudouard reaction (Equation (5)). Increasing pressure favors carbon formation according to Le Chatelier's principle. However, with increasing temperature $\mathrm{CO}$ becomes more stable than $\mathrm{CO}_{2}$ and the reverse reaction is favored consuming solid carbon. Thermodynamic data from ${ }^{6}$.

For more information, the reader is referred to ${ }^{20 \mid 27}$ for coal gasification (or heterogeneous water-gas shift reaction) and to ${ }^{28 \mid 29}$ for the Bergius process $/ \mathrm{CH}_{4}$ cracking.

The aim of this paper is to show that the forward and the reverse reaction rates of equilibrium limited gassolid reactions are generally different from each other and that distinct rate expressions are required to allow accurate process modeling. Thus, the widely used equilibrium limited reaction rate expression (see Equation (1)) is not generally sufficient to describe the reaction rate in both reaction directions. Instead, a new approach is proposed for the derivation of thermodynamically consistent equilibrium limited gas-solid reaction rates that accounts for the difference between the forward and reverse reaction direction. Process simulation is used for a generic gas-solid system to compare the proposed rate expressions to traditional reaction rate equations.

\section{Problem description}

Modeling of chemical processes is often based on a reaction network that is known a priori which describes the chemical transformations that occur in within process units. In these networks the reaction equations are conventionally stated in the direction that they are expected to proceed, i.e. in a steam reformer the steam reforming reaction is used instead of the methanation reaction (the reverse of the steam reforming reaction). Since many traditional processes operate exclusively in the direction that the reaction equations are stated, the reverse reactions are not considered in detail or are described sufficiently accurate by a reversible reaction expression as given by Eq. (1).

However, there are many examples where both reaction directions occur in the same process unit. Chemical looping processes (e.g. the steam-iron process and calcium looping) have received an increasing interest in recent decades for different applications (e.g. carbon capture and sequestration ${ }^{30131}$ or utilization, clean $\mathrm{H}_{2}$ or syngas production ${ }^{5 / 32 / 33}$, etc.). They are often based on the idea of exploiting a single reversible gas-solid reaction repeatedly in the same reactor. Thus, chemical looping processes are inherently dynamic due to the cyclic switching between reduction and oxidation of an oxygen storage material. To understand and exploit these dynamic processes in the form of process optimization a correct description of both reaction directions is necessary in a single model. However, process simulation is often performed stepwise, i.e. the reduction and the oxidation reactions are simulated sequentially ${ }^{34}$ or they occur in different parts of the reactor ${ }^{31 / 35}$. There are only two publications in which the forward and reverse reaction direction were modeled simultaneously in the same reactor ${ }^{36 / 37}$.

Other important scenarios that require accurate modeling of the forward and reverse reaction direction include the start-up and dynamic operation of chemical reactors. For example, coke formation by the Boudouard reaction (as well as $\mathrm{CH}_{4}$ cracking and $\mathrm{CO}$ reduction ${ }^{38}$ ) is known to be a significant problem in steam reforming and methanation reactors ${ }^{39} 41$ among others. At start-up the reactor is relatively cold and coke formation is thermodynamically favored (see Figure 3). After some time the methanation reaction ignites the reactor and the temperature rises significantly (especially at hotspots). Thus, coke gasification is favored. Furthermore, local temperature and composition differences along the spatial coordinates of the reactor could potentially lead to a reversal in the reaction direction of the Boudouard reaction or other gas-solid reactions. Other dynamic scenarios such as a load change may also require the forward and reverse direction of a gas-solid reaction to be described accurately within one single model.

In the examples above both reaction directions (forward and reverse) of the corresponding equilibrium limited gas-solid reactions are important. It is therefore shown in the following how to derive reaction rate expressions that are able to describe both reaction directions in a single model.

\section{Derivation of equilibrium limited rate equations}

In this section the rate expressions for equilibrium limited gas-solid reactions are derived. First, homogeneous 
gas phase reactions are considered and then the theory is expanded to heterogeneous gas-solid reactions. Important differences in the form of the derived equations and their interpretation are highlighted.

The derivation presented here should be viewed as an extension of the derivation of homogeneous gas phase reactions rates toward heterogeneous gas-solid reaction rates. This extension does not give detailed information about reaction pathways and mechanistic steps. However, the main purpose is to illustrate which are the necessary mathematical properties that reaction rate equations for equilibrium limited gas-solid reactions must have to be thermodynamically consistent and phenomenologically correct.

\subsection{Gas phase equilibrium limited reactions}

Consider an arbitrary gas phase reaction that proceeds according to the reaction

$$
a \mathrm{~A}+b \mathrm{~B} \underset{\mathrm{k}_{-}}{\stackrel{\mathrm{k}_{+}}{\rightleftharpoons}} c \mathrm{C}+d \mathrm{D},
$$

where $\mathrm{A}, \mathrm{B}, \mathrm{C}$ and $\mathrm{D}$ are gas phase components and $a, b$, $c$ and $d$ their respective stoichiometric coefficients. The general reaction rate for this equilibrium reaction can be written as

$$
r=r_{+}-r_{-},
$$

where $r$ is the total reaction rate and $r_{+}$and $r_{-}$are the forward and reverse reaction rate, respectively. Assuming elementary reactions, the reaction rates can be expressed as

$$
r=k_{+} p_{\mathrm{A}}^{a} p_{\mathrm{B}}^{b}-k_{-} p_{\mathrm{C}}^{c} p_{\mathrm{D}}^{d}
$$

Here, $k_{+}$and $k_{-}$are the kinetic coefficients for the forward and reverse reaction and $p_{i}$ denotes the partial pressure of each component $i$. At chemical equilibrium the condition $r \stackrel{!}{=} 0$ must hold since the reaction rates of the forward and reverse reaction are equal (dynamic equilibrium). Therefore a relation between the kinetic coefficients and the partial pressures at equilibrium can be derived:

$$
\frac{k_{+}}{k_{-}}=\left(\frac{p_{\mathrm{C}}^{c} p_{\mathrm{D}}^{d}}{p_{\mathrm{A}}^{a} p_{\mathrm{B}}^{b}}\right)_{\mathrm{eq}}
$$

Here, the index eq indicates that all partial pressures are at their respective equilibrium value. The chemical equilibrium constant $K_{\text {eq }}$ is related to the partial pressures of the components at chemical equilibrium by the mass action law according to

$$
K_{\mathrm{eq}}=\prod_{i}\left(\frac{p_{i}}{p^{\ominus}}\right)^{v_{i}}
$$

where $p^{\theta}$ is the standard pressure and $v_{i}$ the stoichiometric coefficient of component $i$. Using Equation (12) on our example reaction yields

$$
K_{\mathrm{eq}}=\left(p^{\ominus}\right)^{(a+b-c-d)}\left(\frac{p_{\mathrm{C}}^{c} p_{\mathrm{D}}^{d}}{p_{\mathrm{A}}^{a} p_{\mathrm{B}}^{b}}\right)_{\mathrm{eq}},
$$

which can be transformed into

$$
\left(\frac{p_{\mathrm{C}}^{c} p_{\mathrm{D}}^{d}}{p_{\mathrm{A}}^{a} p_{\mathrm{B}}^{b}}\right)_{\mathrm{eq}}=\frac{K_{\mathrm{eq}}}{\left(p^{\ominus}\right)^{(a+b-c-d)}}
$$

and inserted in Equation (11) to yield

$$
k_{-}=k_{+} \frac{\left(p^{\ominus}\right)^{(a+b-c-d)}}{K_{\mathrm{eq}}} .
$$

Equation (15) highlights an essential link between chemical kinetics and thermodynamics. It shows that the reaction rate coefficients of the forward and reverse reaction, $k_{+}$and $k_{-}$, are not independent but tied together by the chemical equilibrium constant $K_{\text {eq }}$. Combining Equations (15) and (10) yields a well known form of equilibrium limited reaction rates widely used for modeling of dynamic processes in chemical engineering:

$$
r=k_{+}\left(p_{\mathrm{A}}^{a} p_{\mathrm{B}}^{b}-\left(p^{\ominus}\right)^{(a+b-c-d)} \frac{p_{\mathrm{C}}^{c} p_{\mathrm{D}}^{d}}{K_{\mathrm{eq}}}\right)
$$

According to the preceding derivation, the positive term represents the forward rate and the negative term the reverse rate of the total reaction. Therefore, at chemical equilibrium, the forward and reverse reaction rates are equal. This rate expression holds for the whole range of possible concentrations of the gas components. If the current composition is on the left side of the equilibrium the reaction will proceed in the forward direction. Conversely, the reaction will proceed in the reverse reaction if the current composition is on the right side of the equilibrium. That means that the same fundamental reaction mechanism is assumed for the forward and reverse reaction. For the special case of equimolar reactions (i.e. $a+b-c-d=0$ ), we can simplify Equation (16) since the standard pressure vanishes because $\left(p^{\ominus}\right)^{0}=1$. Furthermore, the total pressure $p$ can be lumped into the rate constant (since $p_{i}=p x_{i}$ ) to yield an expression with regard to the component mole fractions $x_{i}$ :

$$
r=k_{p+}\left(x_{\mathrm{A}}^{a} x_{\mathrm{B}}^{b}-\frac{x_{\mathrm{C}}^{c} x_{\mathrm{D}}^{d}}{K_{\mathrm{eq}}}\right),
$$

where $k_{p+}=k_{+} p^{(a+b)}$.

In the next section an analogous derivation is proposed for equilibrium limited gas-solid reactions. 


\subsection{Gas-solid equilibrium limited reactions}

An arbitrary gas-solid reaction proceeds according to the reaction

$$
a \mathrm{~A}(\mathrm{~g})+b \mathrm{~B}(\mathrm{~s}) \underset{\mathrm{k}_{-}}{\stackrel{\mathrm{k}_{+}}{\rightleftharpoons}} c \mathrm{C}(\mathrm{g})+d \mathrm{D}(\mathrm{s}),
$$

where $\mathrm{A}$ and $\mathrm{C}$ are gaseous and $\mathrm{B}$ and $\mathrm{D}$ are solid components. The following generic kinetic expression is used to describe the total reaction rate:

$$
r=r_{+}-r_{-}=k_{+} p_{\mathrm{A}}^{a} f\left(\Theta_{\mathrm{B}}\right)-k_{-} p_{\mathrm{C}}^{c} f\left(\Theta_{\mathrm{D}}\right) .
$$

Here, $\Theta_{j}$ is an arbitrary parameter (or more generally a parameter vector) that describes the influence of the solid reactant $j$ on the reaction rate (e.g. the surface coverage or the reaction extent with regard to the solid). Furthermore, $f\left(\Theta_{j}\right)$ is a function describing the reaction mechanism with regard to the solid (the reader is referred to ${ }^{42}$ for an overview of important solid-state kinetic models). The functions $f\left(\Theta_{j}\right)$ are not further specified in Equation (19) to keep the derivation as general as possible. The influence of the gas phase partial pressures on the reaction rate is again assumed to be described by the power law (assuming elementary reactions with regard to the gas phase). At chemical equilibrium the condition $r \stackrel{!}{=} 0$ must hold yielding

$$
\frac{k_{+}}{k_{-}} \frac{f\left(\Theta_{\mathrm{B}}\right)}{f\left(\Theta_{\mathrm{D}}\right)}=\left(\frac{p_{\mathrm{C}}^{c}}{p_{\mathrm{A}}^{a}}\right)_{\mathrm{eq}} .
$$

Note that only the partial pressures of the gas phase components are at equilibrium. There is not one single equilibrium composition of the solid phase as it depends on the amount of gas that is present in the system.

Consider the following example: there are two closed systems at $800 \mathrm{~K}$ each with $10 \mathrm{~mol}$ of pure iron. Additionally, systems 1 and 2 initially contain $1 \mathrm{~mol}$ and $5 \mathrm{~mol}$ of $\mathrm{H}_{2} \mathrm{O}$, respectively. After reaching chemical equilibrium (i.e. at $t \rightarrow \infty$ ) the gas phase composition in both systems must be equal according to the equilibrium shown in the Baur-Glaessner diagram $\left(x_{\mathrm{H}_{2} \mathrm{O}} \approx 0.18\right.$, see Figure 1). However, in system 2 a larger amount of iron will be converted into $\mathrm{Fe}_{3} \mathrm{O}_{4}$ according to Eq. (3) since more $\mathrm{H}_{2} \mathrm{O}$ is available for the reaction. Therefore, in system 2 more $\mathrm{Fe}_{3} \mathrm{O}_{4}$ will be present at equilibrium compared to system 1 even though the gas composition is the same because chemical equilibrium is dictated by the gas phase and is not altered by the initial amount of iron in the system (the equilibrium gas phase composition may be different in both systems if other reactions, like the formation of $\mathrm{FeO}$, are considered as well (see Figure 1 at 1100K)).

This fact is also reflected in the calculation of the chemical equilibrium constant for gas-solid systems according to the mass action law (see Eq. (12)) because the solid components $\mathrm{B}(\mathrm{s})$ and $\mathrm{D}(\mathrm{s})$ are omitted on the right hand side of the equation (nevertheless, gas and solid components are included according to their stoichiometry in the calculation of $K_{\text {eq }}$ from the Gibbs energies) ${ }^{43}$. Thus, applying the mass action law to Equation (18) yields:

$$
K_{\mathrm{eq}}=\left(p^{\ominus}\right)^{(a-c)}\left(\frac{p_{\mathrm{C}}^{c}}{p_{\mathrm{A}}^{a}}\right)_{\mathrm{eq}},
$$

Combining Equation (21) and (20) gives

$$
k_{-}=k_{+} \frac{f\left(\Theta_{\mathrm{B}}\right)}{f\left(\Theta_{\mathrm{D}}\right)} \frac{\left(p^{\ominus}\right)^{(a-c)}}{K_{\mathrm{eq}}} .
$$

Similar to the derivation for the homogeneous case, a link between the process kinetics and thermodynamics is established. However, it can be seen that in the heterogeneous case the reverse rate coefficient $\left(k_{-}\right)$is not only dependent on the forward rate coefficient $\left(k_{+}\right)$and the equilibrium constant $\left(K_{\text {eq }}\right)$ but also on the solid composition. Equation (22) for the rate coefficient $k_{-}$can be inserted into Equation (19) to yield

$$
r=k_{+} f\left(\Theta_{\mathrm{B}}\right)\left(p_{\mathrm{A}}^{a}-\left(p^{\ominus}\right)^{(a-c)} \frac{p_{\mathrm{C}}^{c}}{K_{\mathrm{eq}}}\right) .
$$

Comparing Equation (23) and (16) shows that the difference is the term $f\left(\Theta_{\mathrm{B}}\right)$. The term $f\left(\Theta_{\mathrm{B}}\right)$ may be interpreted as a resistance term (see the analogy to Equation (1)) that describes the complexity of the chemical reaction, e.g. according to a Langmuir-Hinshelwood-HougenWatson model. The reaction rate in Equation (23) is proportional to the terms for the influence of the solid $\left(f\left(\Theta_{\mathrm{B}}\right)\right)$ and the gas composition (bracket term in Eq. (23)) which is important to accurately describe the true reaction behavior. If either term is zero, the reaction rate becomes equal to zero regardless of the other term. Another important difference is in the interpretation of the terms. While in the homogeneous case (see Equation (16) the positive and negative terms in the bracket represent the forward and reverse reaction rates, in the heterogeneous case (see Equation (23)) the negative term represents the lowering of the driving force when reaching chemical equilibrium as was argued by $\mathrm{Sohn}^{44}$. For the special case of an equimolar reaction with regard to the gas phase components (i.e. $a=-c$ ), the process pressure $p^{a}$ can be lumped into the rate constant and Equation (23) can be simplified to:

$$
r=k_{p+} f\left(\Theta_{\mathrm{B}}\right)\left(x_{\mathrm{A}}^{a}-\frac{x_{\mathrm{C}}^{c}}{K_{\mathrm{eq}}}\right)
$$

It must be noted that Equation (24) is valid only if the composition is on the left side of equilibrium (i.e. if $\left.x_{\mathrm{C}}^{c} / x_{\mathrm{A}}^{a}<K_{\mathrm{eq}}\right)$ due to the double dependency of the reaction rate on the solid and the gas composition.

The reasoning is as follows: if reaction (18) proceeds 
in the reverse direction (i.e. if $x_{\mathrm{A}}^{a}-x_{\mathrm{C}}^{c} / K_{\mathrm{eq}}<0$ ), the reaction rate as stated in Equation (24) would increase with an increase in the function $f\left(\Theta_{\mathrm{B}}\right)$. Assuming that $f\left(\Theta_{\mathrm{B}}\right)$ is simply described by the solid mole fraction of component $\mathrm{B}$ (i.e. $\left.f\left(\Theta_{\mathrm{B}}\right)=x_{\mathrm{B}}\right)$ it would mean that the reaction rate of the reverse reaction is increasing with the amount of $\mathrm{B}(\mathrm{s})$ present. This is equivalent to saying that the reverse reaction rate is increasing with a decreasing amount of $\mathrm{D}(\mathrm{s})$ (since $\mathrm{B}(\mathrm{s})$ and $\mathrm{D}(\mathrm{s})$ are the only solid components, thus $\left.x_{\mathrm{B}}=1-x_{\mathrm{D}}\right)$. This behavior is improbable since collision theory states that the reaction rate depends on the probability of successful collisions between two reactants. That means that a higher concentration of reactants yields a higher collision probability and, therefore, a higher reaction rate. Equation (24) does not satisfy this requirement for the reverse reaction direction. Thus, Equation (24) can not be applied in the case when $\left(x_{\mathrm{A}}^{a}-x_{\mathrm{C}}^{c} / K_{\mathrm{eq}}\right)<0$ since it does not yield a phenomenologically consistent behavior for the reverse reaction direction. Note that we chose the equimolar case (Equation (24)) here for explanatory reasons because it is easier to understand. However, the reasoning is generally the same for non-equimolar reactions as well.

An appropriate rate expression for the reverse reaction $r^{\prime}$ can be derived by stating reaction Equation $(18)$ in the reverse direction:

$$
c \mathrm{C}(\mathrm{g})+d \mathrm{D}(\mathrm{s}) \stackrel{\mathrm{k}_{-}}{\underset{\mathrm{k}_{+}}{\rightleftharpoons}} a \mathrm{~A}(\mathrm{~g})+b \mathrm{~B}(\mathrm{~s})
$$

The previously outlined approach can now be used for the derivation of the following rate expression for the reverse reaction:

$$
r^{\prime}=k_{p-} f\left(\Theta_{\mathrm{D}}\right)\left(x_{\mathrm{C}}^{c}-\frac{x_{\mathrm{A}}^{a}}{K_{\mathrm{eq}}^{\prime}}\right)
$$

Note that the equilibrium constant $K_{\mathrm{eq}}^{\prime}$ is different from the previously defined $K_{\text {eq }}$ for the forward reaction (see Equation 23) because of the different stoichiometry. However, the relationship between both variables is easily established as $K_{\text {eq }}^{\prime}=1 / K_{\text {eq }}$ because only the signs of the stoichiometric coefficients are reversed, yielding

$$
r^{\prime}=k_{p-} f\left(\Theta_{\mathrm{D}}\right)\left(x_{\mathrm{C}}^{c}-K_{\mathrm{eq}} x_{\mathrm{A}}^{a}\right)
$$

It can be seen that the reaction rate $r^{\prime}$ is now dependent on the rate coefficient for the reverse reaction, $k_{p-}$, instead of $k_{p+}$. Furthermore, Equation (27) is dependent on $f\left(\Theta_{\mathrm{D}}\right)$ instead of $f\left(\Theta_{\mathrm{B}}\right)$ (Equation (24)). This fact is in line with Sohn's proposition that the forward and reverse reaction of equilibrium limited gas-solid reactions generally follow different reaction mechanisms ${ }^{44}$. Note that Equation (27) is only valid for the reverse direction of reaction Equation (18), i.e. if $\left(x_{\mathrm{C}}^{c}-K_{\text {eq }} x_{\mathrm{A}}^{a}\right)<0$ for the same reason that was used for the forward reaction rate.

The fundamental difference between the derivation of rate expressions for equilibrium limited gas phase and gas-solid reactions stems from the second term due to the influence of the solid composition on the reaction rate which can be viewed mathematically as a "driving force" (the real thermodynamic driving force is always in the direction of decreasing Gibbs free energy). In gas phase equilibrium limited reactions the reaction rate is dependent only on the gas composition and its deviation from the equilibrium composition. For gas-solid equilibrium limited reactions the solid composition is equally important and represents a second dimension in the reaction rate that is independent of the gas composition. Therefore, using the outlined approach in Section 3.1 for gas phase equilibrium limited reactions the same effective rate expression is obtained regardless of whether the approach is applied to Equation (8) or its reverse since the reaction rate is only dependent on the gas phase composition. However, the same is not true for the proposed approach in Section 3.2 for gas-solid equilibrium limited reactions, where two different reaction rate expressions will emerge as a consequence of the two distinct terms for the solid and gas composition.

Since the derived reaction rates for the forward and the reverse direction of reaction (18) are both valid only on the left or on the right side of equilibrium, respectively, a single piecewise-defined reaction rate $\left(r_{+_{-}}\right)$can be expressed for reaction (18) that is valid on both sides of chemical equilibrium:

$$
r_{+-}= \begin{cases}k_{p+} f\left(\Theta_{\mathrm{B}}\right)\left(x_{\mathrm{A}}^{a}-\frac{x_{\mathrm{C}}^{c}}{K_{\mathrm{eq}}}\right) & \text { if } x_{\mathrm{C}}^{c} / x_{\mathrm{A}}^{a} \leq K_{\mathrm{eq}} \\ -k_{p-} f\left(\Theta_{\mathrm{D}}\right)\left(x_{\mathrm{C}}^{c}-K_{\mathrm{eq}} x_{\mathrm{A}}^{a}\right) & \text { if } x_{\mathrm{C}}^{c} / x_{\mathrm{A}}^{a}>K_{\mathrm{eq}}\end{cases}
$$

In this way a different reaction mechanism is active depending on whether the current gas composition is on the left or right side of chemical equilibrium. If the current gas composition is on the left side of equilibrium, the reaction rate is positive. However, if the current gas composition is on the right side of equilibrium, the reaction rate is negative, i.e. the reaction proceeds in the reverse direction.

Equation (28) is fundamentally different from traditional modeling approaches where either the forward and reverse reaction rate are active simultaneously for any given composition or only one single reversible reaction mechanism is active. However, it will be shown in Section 5 that the piecewise-defined function (see Equation (28) leads to a thermodynamically consistent formulation (i.e. it satisfies the two conditions mentioned in the Section 1) and also accounts for the possibility of different reaction mechanisms for the forward and reverse reaction direction of an equilibrium limited gas-solid reaction. Furthermore, the thermodynamic implications of using this formulation as opposed to traditional reaction rates of the form of Eq. (1) will be discussed in the next section. 


\section{Discussion}

The difference between Equations (17) and (28) is illustrated exemplary in Figure 4. While the blue line

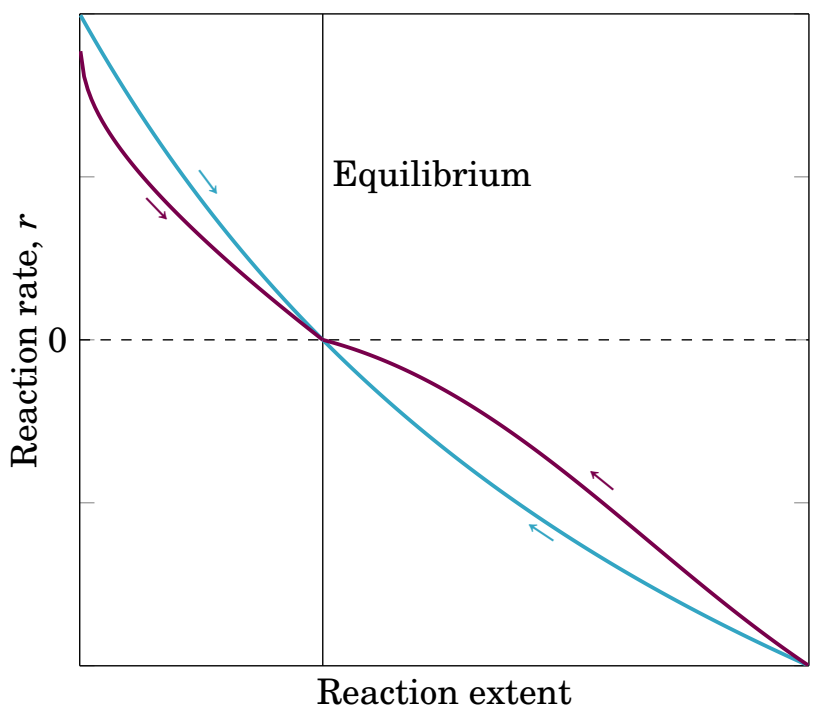

Figure 4: Exemplary reaction rate as a function of reaction extent. The reaction rate of an equilibrium limited gas phase reaction according to an equation of the form (17) (blue) is compared to the proposed, piecewisedefined formulation (Eq. (28) ) allowing for different mechanisms on either side of chemical equilibrium (red). The kink in the red line at equilibrium indicates the change in the reaction mechanism.

(for equilibrium limited homogeneous gas phase reactions) shows a smooth behavior for the whole composition range, the red line (for equilibrium limited gas-solid reactions) has a kink at chemical equilibrium which is due to the piecewise definition of Eq. (28). Both sides of Equation (28) yield $r=0$ at chemical equilibrium, i.e. they satisfy the thermodynamic consistency condition (see Section 11. However, the kink in the reaction rate is an unnatural phenomenon, since the underlying thermodynamic driving force, the Gibbs free energy, is a smooth function over the whole composition range. This is exploited for example in Gibbs free energy minimization techniques for finding chemical equilibrium. Moreover, the law of microscopic reversibility states that for elementary reactions (and also for every single elementary reaction step in complex reactions) the preferred reaction pathway for the forward reaction must also be preferred for the reverse reaction in the vicinity of chemical equilibrium ${ }^{45}$. Therefore, the reaction rate should be a smooth function (i.e. without kink). This aspect in naturally included in a detailed micro-kinetic description. However, micro-kinetic descriptions are usually much too complex for process modeling purposes, especially for the dynamic description of processes and process optimization which requires a fairly fast solution of the involved process model. Thus, a trade-off between ther- modynamic accuracy and model size/complexity must be found for each purpose. We argue that especially for dynamic simulation and optimization purposes, a macroscopic description (in contrast to a micro-kinetic description) in the form of Equation (28) gives a reasonable trade-off in favor of model size/complexity without sacrificing too much thermodynamic detail. It was discussed in Section 2 and by Sohn in a recent publication ${ }^{44}$ that the real reaction rate on the left side of equilibrium is generally different from the reaction rate on the right side of chemical equilibrium. Equation (28) allows for this possibility. The main limitation or error in Eq. (28) is expected to be in the vicinity of chemical equilibrium because the piecewise definition does not accurately describe the thermodynamic reality in this region. If this error can be tolerated must be discussed for each individual problem. However, especially for problems in which an equilibrium limited reaction is exploited in both reaction directions far from chemical equilibrium (e.g. chemical looping processes as discussed in Section (1), it is important to account for the change in the reaction mechanism as will be discussed further in the next section.

\section{Case studies}

In the following we will show by a generic example the benefits of using the proposed piecewise-defined reaction rates in process modeling and simulation compared to traditional approaches. For ease of understanding we chose an equimolar reaction as an example. Note, however, that the results presented here are equally applicable to non-equimolar reactions as well.

\subsection{Simple reactor model}

A simplified pseudo-homogeneous reactor model for the equilibrium limited gas-solid reaction

$$
\mathrm{A}(\mathrm{g})+\mathrm{B}(\mathrm{s}) \underset{\mathrm{k}_{-}}{\stackrel{\mathrm{k}_{+}}{\rightleftharpoons}} \mathrm{C}(\mathrm{g})+\mathrm{D}(\mathrm{s})
$$

is given by the following set of equations:

$$
\begin{aligned}
\frac{\mathrm{d} x_{i}}{\mathrm{~d} t} & =\frac{\dot{F}(t)}{V_{\mathrm{R}}}\left(x_{i}^{(\mathrm{in})}(t)-x_{i}\right)+\frac{m_{\mathrm{S}}}{c_{t, g} V_{\mathrm{R}}} \sum_{k}^{N_{R}} v_{i, k} r_{k} \\
\forall i & =\{\mathrm{A}, \mathrm{C}\} \\
\frac{\mathrm{d} x_{j}}{\mathrm{~d} t} & =M_{\mathrm{S}} \sum_{k}^{N_{R}} v_{j, k} r_{k} \\
\forall j & =\{\mathrm{B}, \mathrm{D}\}
\end{aligned}
$$

Equation (30) is the mass balance of the gas phase with $x_{i}$ being the mole fraction of gas phase component $i, t$ the relative time, $\dot{F}(t)$ the time dependent volumetric flow rate, $V_{\mathrm{R}}$ the reactor volume, $x_{i}^{(\mathrm{in})}(t)$ the time dependent inlet mole fraction of component $i, m_{\mathrm{S}}$ the amount of solids in the reactor, $c_{t, g}$ the total gas concentration, 
$N_{R}$ the total number of reactions, $v_{i, k}$ the stoichiometric factor of component $i$ in reaction $k$ and $r_{k}$ the reaction rate of reaction $k$. Equation (31) is the mass balance of the solid phase with $x_{j}$ being the mole fraction of the solid phase component $j$ and $M_{\mathrm{S}}$ the molar mass of the solid. An illustration of the reactor model is shown in Figure 5. The model assumes a bulk solid phase that

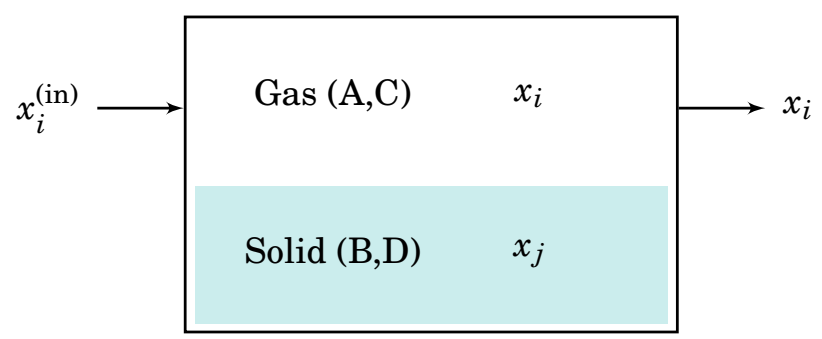

Figure 5: Illustration of the simple reactor model. The gas and solid phase are denoted by G and S, respectively. Gas flows into the reactor with a composition $x_{i}^{\text {(in) }}(t)$ and reacts with the stagnant solid. The volumetric flow $\dot{F}$ can be set to zero to switch from semi-batch (continuously flowing gas and stagnant solid) to batch mode (stagnant gas and solid).

is exposed to a continuous gas flow with a time dependent composition, $x_{i}^{(\mathrm{in})}(t)$, and flow rate, $\dot{F}(t)$. The gas flow can be turned off or on by setting the value of $\dot{F}(t)$ to either zero or any value greater than zero, respectively. By turning off the gas flow the reactor is switched from semi-batch (continuously flowing gas and stagnant solid) to batch mode (stagnant gas and solid). Constant temperature and pressure is assumed in the reactor, so that $c_{t, g}=$ const.. Diffusion resistances from the gas to the solid phase and inside the solid phase are neglected for simplicity since only the qualitative kinetic and thermodynamic properties of the model are of interest for this general analysis.

\subsection{Dynamic reactor operation}

To analyze and compare different modeling approaches to the approach proposed in this work, a dynamic reactor operation strategy is proposed (see Figure 6). The reactor is assumed to start in batch mode (i.e. $\dot{F}=0$, no gas or solid flow) with pure components $\mathrm{A}$ and $\mathrm{B}$ in the gas and the solid phase, respectively. At time $t=20$ the gas flow is activated $(\dot{F}=1)$ switching the reactor to semi-batch mode (gas flows over stagnant solid). The inlet gas consists of $5 \mathrm{~mol} \% \mathrm{~A}$ and $95 \mathrm{~mol} \% \mathrm{~B}$, thereby favoring the reverse reaction. At time $t=40$ the inlet gas composition is switched to $70 \mathrm{~mol} \% \mathrm{~A}$ and $30 \mathrm{~mol} \% \mathrm{~B}$ to again favor the forward reaction. This dynamic operation strategy ensures that different reactor operation scenarios are covered at once. The validity of the proposed reaction rate expressions can be assessed and compared against alternative expressions using process simulation.

The dynamic operation strategy is simulated in three studies with different reaction rate expressions each. Table 1 summarizes the three studies simulated in this work. For simplicity (but without loss of generality), it is assumed for all three studies that $f\left(\Theta_{\mathrm{B}}\right)$ is be equal to the solid mole fraction $x_{\mathrm{B}}$ (and equivalently $f\left(\Theta_{\mathrm{D}}\right)=x_{\mathrm{D}}$ ). In study 1 only the forward reaction rate expression (see Equation (24)) is active in the simulation. Equilibrium limitation is accounted for in the bracket term. Study 2 uses reaction rates for the forward and reverse direction that do not explicitly account for chemical equilibrium. However, the values forward and reverse kinetic coefficients $\left(k_{p+}\right.$ and $k_{p-}$, respectively) satisfy the equilibrium relationship for the gas phase $K_{\mathrm{eq}}=k_{p+} / k_{p-}$ (see Equation (15)). It can be shown that for a homogeneous gas phase reaction (see derivation in Section 3.1) this would be equivalent to using a single reversible reaction rate (as used in study 1). Lastly, study 3 uses the piecewisedefined rate expression derived in this work (see Equation (28)).

\subsection{Simulation results}

The aim of the simulation studies is to qualitatively assess the thermodynamic consistency of the proposed reaction rate expressions. Therefore, the process parameters are set to arbitrary values which are summarized in Table 2. The three example studies in Table 1 were simulated using Matlab's ode23 solver (version 2017b).

Figure 7 shows the results for simulation study 1 . In phase I (forward reaction favored), the solid component $\mathrm{B}$ is partially transformed into D according to Equation (29). Since there is not enough gas to fully convert the solid, the gas phase composition reaches its equilibrium composition at $x_{\mathrm{A}}=0.333$ and $x_{\mathrm{C}}=0.667$ (for $K_{\text {eq }}=2$ ) and the reaction halts which is phenomenologically correct. In phase II, however, the solid mole fractions quickly escape the physically defined region between zero and one because the reverse direction is favored but the rate is still dependent on the amount of $\mathrm{B}$ which is steadily increasing instead converging to one. Therefore, the reaction never halts but goes on infinitely, which is false. In phase III the correct phenomenological behavior is observed again because the forward reaction is favored. Since the reactor is now in semi-batch mode (compared to phase I), enough gas is available to fully convert B to D and the reaction comes to a halt. Thus, the final gas concentration is equal to the inlet concentration. It can be concluded that Equation (24) yields false predictions if the reverse reaction is favored and can even lead to physically impossible results. Thus, Equation (24) must not be used for modeling if both reaction directions are considered.

The simulation results of study 2 are shown in Figure 8 . This study is included because using two reaction rate equations for the forward and reverse direction simultaneously would yield correct results for a homoge- 


\section{Phase I}

$0 \leq t<20$

\begin{tabular}{|c|}
\hline Gas \\
Solid \\
\hline
\end{tabular}

Batch mode (forward reaction favored)
Phase II

$20 \leq t<40$

$x_{\mathrm{A}}^{(\mathrm{in})}=5 \%$
$x_{\mathrm{C}}^{(\mathrm{in})}=95 \%$$\longrightarrow \begin{aligned} & \text { Gas } \\ & \text { Solid }\end{aligned} \longrightarrow x_{i}(t)$

Semi-batch mode (reverse reaction favored)
Phase III

$40 \leq t \leq 80$

$x_{\mathrm{A}}^{(\mathrm{in})}=70 \%$
$x_{\mathrm{C}}^{(\mathrm{in})}=30 \%$$\rightarrow \begin{gathered}\text { Gas } \\ \text { Solid }\end{gathered} \longrightarrow x_{i}(t)$

Semi-batch mode

(forward reaction favored)

Figure 6: Illustration of the test operating sequence. For $0 \leq t<20$ the reactor is in batch mode starting with pure $\mathrm{A}$ and $\mathrm{B}(\mathrm{s})$. Then the gas inlet is activated (semi-batch mode) with a composition favoring the reverse reaction for $20 \leq t<40$. In the last step, the gas composition is switched again to favor the forward reaction for $40 \leq t \leq 80$.

Table 1: Overview of process simulation studies. Study 1 uses only one rate expression for the forward direction. In study 2 reaction rates for the forward and reverse direction are active simultaneously. Study 3 uses the proposed piecewise-defined reaction rate expression.

\begin{tabular}{cllll}
\hline Study & Considered reaction(s) & Stoichiometric matrix & Reaction rate expression $(\mathrm{s})$ \\
\hline 1 & $\mathrm{~A}(\mathrm{~g})+\mathrm{B}(\mathrm{s}) \rightleftharpoons \mathrm{C}(\mathrm{g})+\mathrm{D}(\mathrm{s})$ & $v_{i, k}=\left[\begin{array}{cccc}-1 & -1 & 1 & 1\end{array}\right]^{\top}$ & $r_{1}=k_{p+} x_{\mathrm{B}}\left(x_{\mathrm{A}}-\frac{x_{\mathrm{C}}}{K_{\mathrm{eq}}}\right)$ \\
\hline 2 & $\mathrm{~A}(\mathrm{~g})+\mathrm{B}(\mathrm{s}) \rightleftharpoons \mathrm{C}(\mathrm{g})+\mathrm{D}(\mathrm{s})$ & $v_{i, k}=\left[\begin{array}{cccc}-1 & -1 & 1 & 1 \\
1 & 1 & -1 & -1\end{array}\right]^{\top}$ & $\begin{array}{l}r_{1}=k_{p+} x_{\mathrm{B}} x_{\mathrm{A}} \\
r_{2}=k_{p-} x_{\mathrm{D}} x_{\mathrm{C}}\end{array}$ \\
\hline $\mathrm{C}(\mathrm{g})+\mathrm{D}(\mathrm{s}) \rightleftharpoons \mathrm{A}(\mathrm{g})+\mathrm{B}(\mathrm{s})$ & $\mathrm{A}(\mathrm{g})+\mathrm{B}(\mathrm{s}) \rightleftharpoons \mathrm{C}(\mathrm{g})+\mathrm{D}(\mathrm{s})$ & $v_{i, k}=\left[\begin{array}{llll}-1 & -1 & 1 & 1\end{array}\right]^{\top}$ & $r_{1}= \begin{cases}k_{p+} x_{\mathrm{B}}\left(x_{\mathrm{A}}-\frac{x_{\mathrm{C}}}{K_{\mathrm{eq}}}\right) & \text { if } x_{\mathrm{C}} / x_{\mathrm{A}} \leq K_{\mathrm{eq}} \\
-k_{p-} x_{\mathrm{D}}\left(x_{\mathrm{C}}-x_{\mathrm{A}} K_{\mathrm{eq}}\right) & \text { if } x_{\mathrm{C}} / x_{\mathrm{A}}>K_{\mathrm{eq}}\end{cases}$ \\
\hline
\end{tabular}

Table 2: Parameter values for the simple reactor model given by Equations (30) and (31) and Table 1.

\begin{tabular}{ll}
\hline Parameter & Value \\
\hline$V_{\mathrm{R}}$ & 1 \\
$m_{\mathrm{S}}$ & 0.2 \\
$c_{t, g}$ & 0.15 \\
$M_{\mathrm{S}}$ & 0.8 \\
$\dot{F}$ & 0 for $t<20$ \\
$k_{p+}$ & 1 for $20 \leq t<60$ \\
$k_{p-}$ & 1 \\
$K_{\mathrm{eq}}$ & 0.5 \\
\hline
\end{tabular}

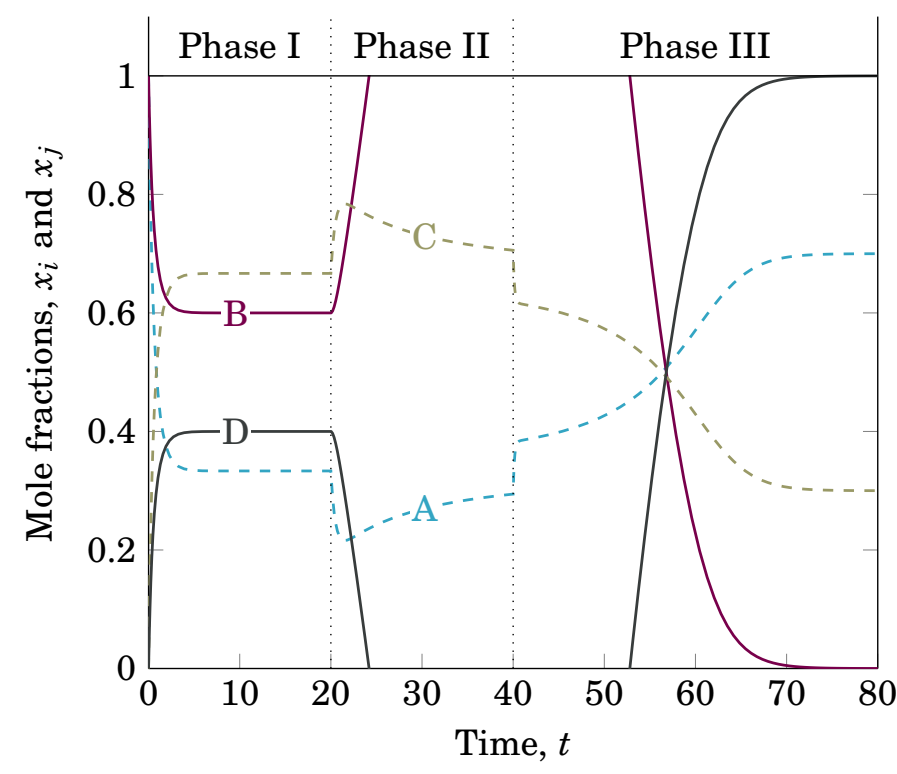

Figure 7: Results of simulation study 1 with kinetic equations as defined in Table 1 with parameters from Table 2. Mole fractions of gases (dashed) and solids (solid) as a function of time. 
neous gas phase reaction if $K_{\mathrm{eq}}=k_{p+} / k_{p-}$ (see Equation (15)) holds and if the reaction rates are described by the power law (see Section 3.1 for further details). However, for gas-solid reactions this approach is not valid. Even though the simulation results in Figure 8 seem to show a phenomenologically reasonable behavior and the composition stays inside the physically defined region, the thermodynamic constraints are never met. In phase I, the reaction proceeds in the forward direction but the reaction does not stop at the thermodynamic equilibrium composition for the gas. In phase II and III the solid is never transformed totally even though enough gas is present in the system due to the activated gas flow. Therefore, using two reaction rates for the forward and reverse reaction simultaneously yields false predictions for every scenario considered in this work.

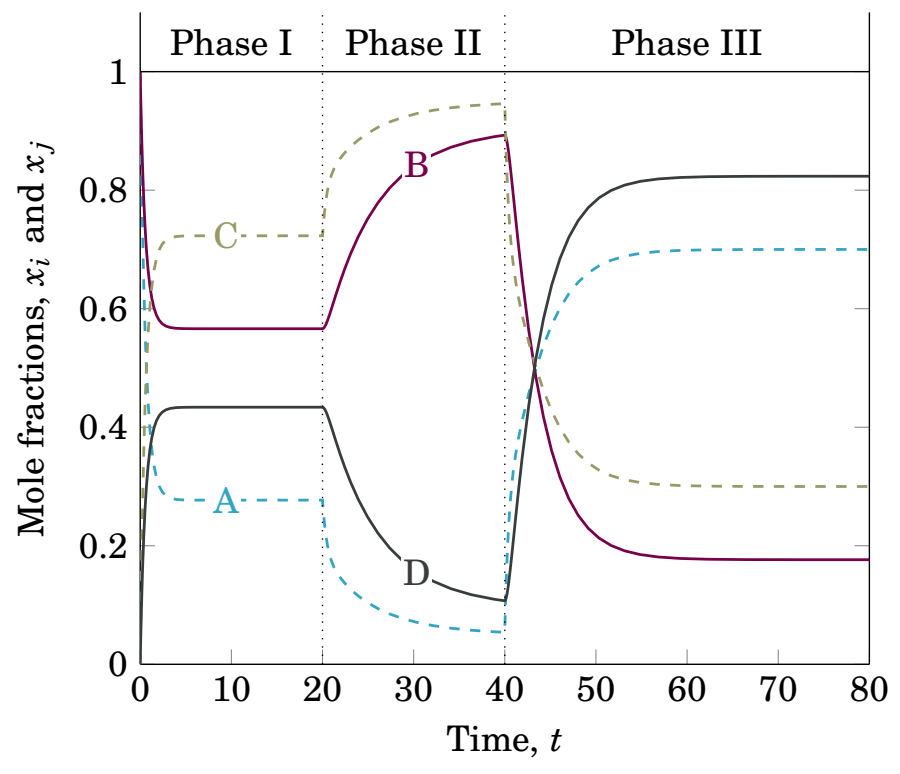

Figure 8: Results of simulation study 2 with kinetic equations as defined in Table 1 with parameters from Table 2. Mole fractions of gases (dashed) and solids (solid) as a function of time.

In contrast, the simulation results of study 3 (see Figure 9) show that the proposed piecewise-defined reaction rate Equation (28) leads to a thermodynamically and phenomenologically sound behavior since only one reaction rate is active at a time depending on the actual gas composition in the reactor. The simulation results in Figure 9 show the qualitative behavior that would be expected. During phase I, the solid phase is gradually transformed from B to D until the available gas is depleted and the reaction stops (equal to the results from simulation study 1). By activating the gas flow and changing the gas composition in phase II the reverse reaction is favored and the solid component $\mathrm{D}$ is transformed back into $\mathrm{B}$. The reaction comes to a halt when the solid is totally transformed from $\mathrm{D}$ to $\mathrm{B}$. The gas composition at the end of phase II is equal to the inlet gas composition since the reaction rate is zero. In phase
III the forward reaction is favored again and B is fully transformed to $\mathrm{D}$ (see also results from simulation study $1)$.

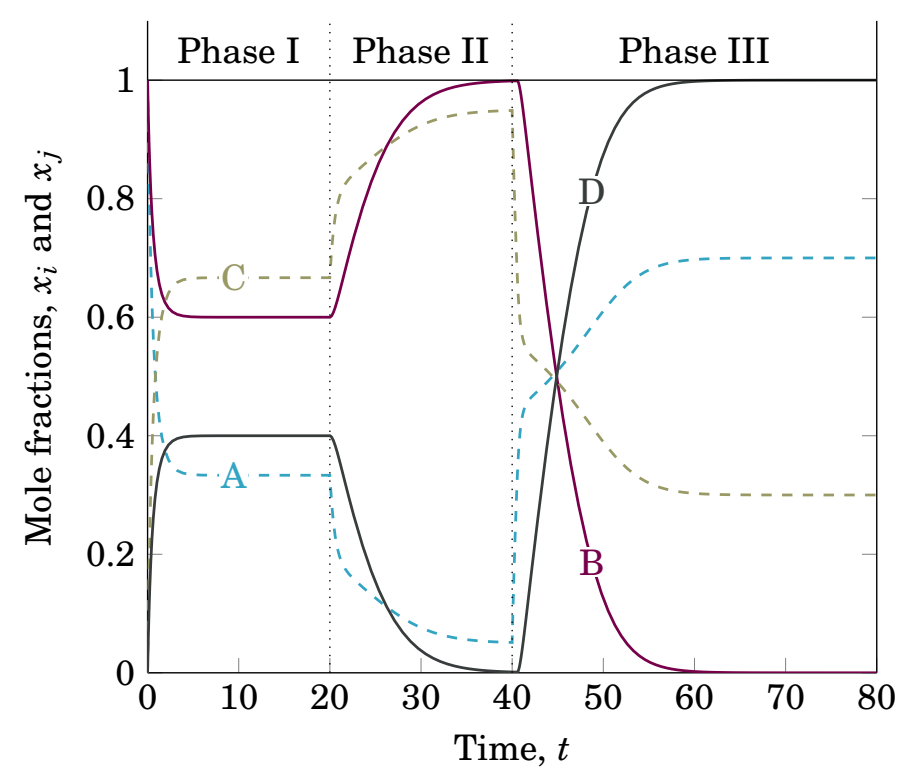

Figure 9: Results of simulation study 3 with kinetic Equations as defined in Table 1 with parameters from Table 2. Mole fractions of gases (dashed) and solids (solid) as a function of time.

To summarize, it is shown by a simple example model that the piecewise-defined rate expression derived in this work gives thermodynamically and phenomenologically correct results under all considered dynamic operating conditions.

\section{Numerical aspects}

While Equation (28) may be used directly for simulation purposes in some cases, the piecewise definition can often lead to numerical problems since dynamic chemical engineering systems are usually described by (partial) differential equation systems. Solving these equation systems typically requires explicit or implicit numerical solvers since analytical solutions can only be obtained for very simple models. Using a piecewise-defined expression for the reaction rates as in Equation (28) leads to a sudden change (non-smoothness) in the reaction rate when the gas composition changes from one side of equilibrium to the other. This non-smooth change in the reaction rate may lead to a crash in standard numerical solvers since the derivative, which is usually used for integration purposes, jumps at the non-smoothness. Furthermore, many standard optimization methods (e.g. Newton's method, sequential quadratic programming or interior point methods) require functions that are twice continuously differentiable since information of the gradient and the Hessian are used (or at least approximated) for finding optima. However, for the piecewisedefined reaction rate expression given by Equation (28) 
the gradient and the Hessian with respect to the gas composition are not uniquely defined, i.e. the piecewisedefined reaction rate expression is not continuously differentiable.

In those cases, relaxation techniques can be used to "smooth" the piecewise-defined rate expressions by using a continuously differentiable "switching function". For a given function, $f(x)$, the main idea is to find an approximation function, $f_{\text {app }}(x, \eta)$ (where $\eta$ is a smoothing parameter), such that $f_{\text {app }}(x, \eta) \rightarrow f(x)$ for $\eta \rightarrow 0$. For example, using a sigmoidal function to approximate Equation (28) leads to the following equation:

$$
\begin{aligned}
& r_{+-}=r \cdot\left(0.5-0.5 \frac{x_{\mathrm{C}}-\frac{K_{\mathrm{eq}}}{1+K_{\mathrm{eq}}}}{\sqrt{\left(x_{\mathrm{C}}-\frac{K_{\mathrm{eq}}}{1+K_{\mathrm{eq}}}\right)^{2}+\eta}}\right) \\
& -r^{\prime} \cdot\left(0.5+0.5 \frac{x_{\mathrm{C}}-\frac{K_{\mathrm{eq}}}{1+K_{\mathrm{eq}}}}{\sqrt{\left(x_{\mathrm{C}}-\frac{K_{\mathrm{eq}}}{1+K_{\mathrm{eq}}}\right)^{2}+\eta}}\right)
\end{aligned}
$$

Here, $r$ and $r^{\prime}$ are the reaction rates for the forward and reverse direction as given by Equations (24) and (27), respectively. The parameter $\eta$ is used to adjust the "smoothness" of the function. Figure 10 shows the

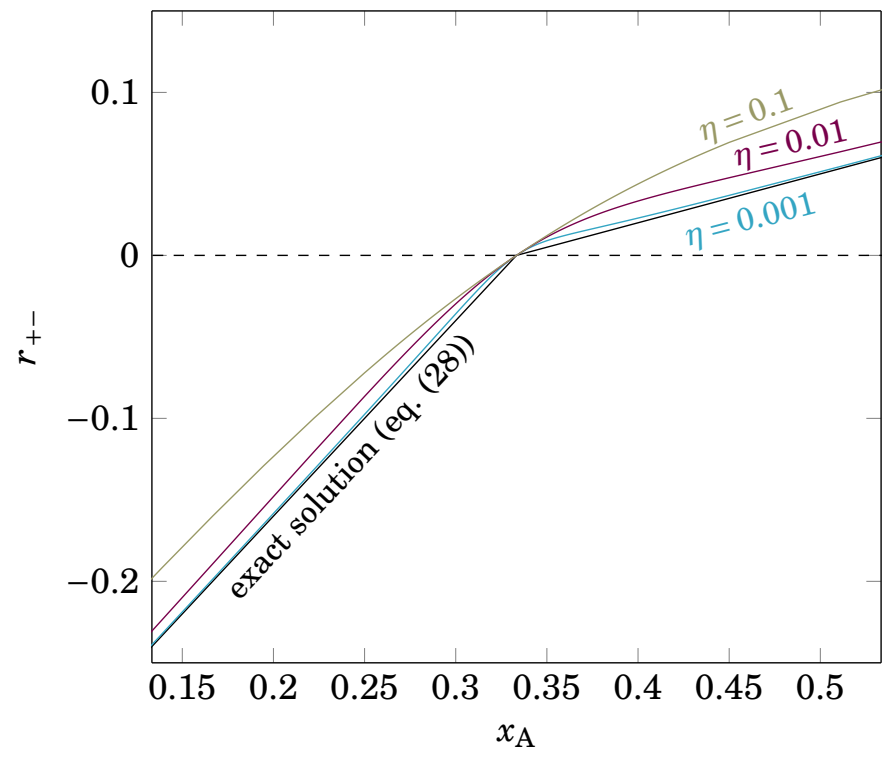

Figure 10: Exact solution of the piecewise-defined reaction rate Equation (28) compared to the sigmoidal approximation function given by equation (32) for various values of $\eta$.

difference between the original reaction rate Equation (28) and the sigmoidal approximation Equation (32) for various values of $\eta$ for $K_{\mathrm{eq}}=2$ and $x_{\mathrm{B}}=0.2$. The original reaction rate Equation (28) exhibits a kink at $r=0$. Thus, Equation (28) is continuous, but it is not continuously differentiable. On the other hand, the approximation function given by (32) is continuously differentiable over the entire composition range. The forward reaction is favored (positive values for $r$ ) as long as $x_{\mathrm{C}} / x_{\mathrm{A}} \leq K_{\mathrm{eq}}$. Otherwise the reverse reaction is favored which leads to negative values for $r$. Increasing the value of $\eta$ for the approximation function (Eq. (32)) leads to a "smoother" function (which is usually easier to solve by standard numerical solvers) but simultaneously the approximation accuracy is reduced. Nevertheless, the thermodynamic equilibrium point is exactly satisfied regardless of the value for $\eta$. It is the process modeler's responsibility to choose a value for $\eta$ that provides a reasonable trade-off between accuracy and numerical stability $\underline{46}$.

\section{Conclusion}

The proposed derivation for thermodynamically consistent and phenomenologically sound reaction rates for equilibrium limited gas-solid reactions includes the following main steps:

- convert each equilibrium limited gas-solid reaction equation into two reaction equations, one for the forward and one for the reverse direction

- use principles similar to homogeneous reactions to derive thermodynamically consistent rate expressions for the forward and the reverse reaction

- combine the resulting rate expressions for the forward and reverse reaction rate into one equation using a piecewise definition

- use numerical relaxation techniques for process modeling if necessary (see Section 6)

Increasing evidence suggests that even heterogeneously catalyzed gas phase reactions like the RWGS reaction exhibit different overall reaction mechanisms in the forward and reverse direction far away from chemical equilibrium ${ }^{47}$, indicating that the outlined approach in this work may not be restricted to equilibrium limited gas-solid reactions but extends to other equilibrium limited reactions as well.

Modeling and simulation of chemical transformation units requires accurate understanding of the reaction kinetics. When using lumped kinetic expressions for overall reactions (as is customary in chemical engineering), the difference between the reaction mechanism of the forward and reverse direction must not be neglected to obtain a physically sound model. This leaves two choices for process modeling:

(1) Use traditional reaction rate expressions and make sure that only the desired reaction direction is active and that the reverse reaction never occurs. This is possible in principle but this approach can not be applied to specific scenarios. Dynamic scenarios with changing inlet gas compositions and/or temperature and pressure changes could lead to a reversal of the reaction direction (by a 
change of the chemical equilibrium composition) which would violate the model.

(2) Use the approach outlined in this work for the simulation and analysis of complex, dynamic scenarios using only one model that is valid for the whole range of possible compositions, temperatures and pressures.

\section{Acknowledgements}

The help of Erdal Aydin, Nicolas Maximilian Kaiser and Jennifer Uebbing in revising the manuscript are gratefully acknowledged.

\section{References}

[1] Kenneth George Denbigh. The Principles of Chemical Equilibrium: With Applications in Chemistry and Chemical Engineering. Cambridge University Press, Cambridge Eng. and New York, 4th edition, 1981.

[2] Guy B. Marin and Gregory S. Yablonsky. Kinetics of Chemical Reactions: Decoding Complexity. WileyVCH Verlag, Weinheim Germany, 2011.

[3] Franz Oeters, Manfred Ottow, Dieter Senk, Ali Beyzavi, Jochen Güntner, Hans Bodo Lüngen, Manfred Koltermann, and Andreas Buhr. Iron, 1. Fundamentals and Principles of Reduction Processes. Wiley-VCH Verlag GmbH \& Co. KGaA, 2000.

[4] Messerschmitt. Verfahren zur Erzeugung von Wasserstoff durch abwechselnde Oxidation und Reduktion von Eisen in von außen beheizten, in den Heizräumen angeordneten Zersetzern, 1911.

[5] Viktor Hacker, Robert Fankhauser, Gottfried Faleschini, Heidrun Fuchs, Kurt Friedrich, Michael Muhr, and Karl Kordesch. Hydrogen production by steam-iron process. Journal of Power Sources, 86 (1-2):531-535, 2000. ISSN 03787753. doi: 10.1016/ S0378-7753(99)00458-9.

[6] M. W. Chase. NIST-JANAF Thermochemical Tables, volume 9 of Journal of Physical and Chemical Reference Data. Monograph. American Chemical Society and the American Institute of Physics for the National Institute of Standards and Technology, Washington, DC, 4th edition, 1998.

[7] Ludwig von Bogdandy and H.-J. Engell. Die Reduktion der Eisenerze: Wissenschaftliche Grundlagen und technische Durchführung. Springer Berlin Heidelberg, Berlin, 2013.

[8] Haitao Wang and H. Y. Sohn. Hydrogen reduction kinetics of magnetite concentrate particles relevant to a novel flash ironmaking process. Metallurgical and Materials Transactions B, 44(1):133-145, 2013. ISSN 1073-5615. doi: 10.1007/s11663-012-9754-z.

[9] Zhixue Yuan, Hong Yong Sohn, and Miguel OlivasMartinez. Re-oxidation kinetics of flash-reduced iron particles in $\mathrm{h} 2-\mathrm{h} 2 \mathrm{o}(\mathrm{g})$ atmosphere relevant to a novel flash ironmaking process. Metallurgical and Materials Transactions B, 44(6):1520-1530, 2013. ISSN 1073-5615. doi: 10.1007/s11663-013-9910-0.

[10] P. C. Hewlett and F. M. Lea. Lea's Chemistry of Cement and Concrete. London, 4th edition, 1998.

[11] Martyn Kenny and Tony Oates. Lime and Limestone. Wiley-VCH Verlag GmbH \& Co. KGaA, 2000.

[12] Ronald Barker. The reversibility of the reaction caco3=cao+co2. Journal of Applied Chemistry and Biotechnology, 23(10):733-742, 1973. ISSN 03759210. doi: 10.1002/jctb.5020231005.

[13] A. Silaban, M. Narcida, and D. P. Harrison. Characteristics of the reversible reaction between co2(g) and calcined dolomite. Chemical Engineering Communications, 146(1):149-162, 1996. ISSN 00986445. doi: 10.1080/00986449608936487.

[14] B. R. Stanmore and P. Gilot. Review-calcination and carbonation of limestone during thermal cycling for co2 sequestration. Fuel Processing Technology, 86(16):1707-1743, 2005. ISSN 03783820. doi: 10.1016/j.fuproc.2005.01.023.

[15] G. Grasa, I. Martínez, M. E. Diego, and J. C. Abanades. Determination of cao carbonation kinetics under recarbonation conditions. Energy \& Fuels, 28(6):4033-4042, 2014. ISSN 0887-0624. doi: 10.1021/ef500331t.

[16] J. M. Valverde, P. E. Sanchez-Jimenez, and L. A. Perez-Maqueda. Limestone calcination nearby equilibrium: Kinetics, cao crystal structure, sintering and reactivity. The Journal of Physical Chemistry $C, 119(4): 1623-1641,2015$. ISSN 1932-7447. doi: $10.1021 / \mathrm{jp} 508745 \mathrm{u}$.

[17] Marcin Broda, Roberta Pacciani, and Christoph R. Müller. $\mathrm{CO}_{2}$ capture via cyclic calcination and carbonation reactions. In An-Hui Lu and Sheng Dai, editors, Porous Materials for Carbon Dioxide Capture, Green Chemistry and Sustainable Technology, pages 181-222. Springer Berlin Heidelberg, Berlin, Heidelberg, 2014.

[18] Mohammad Ramezani, Priscilla Tremain, Elham Doroodchi, and Behdad Moghtaderi. Determination of carbonation/calcination reaction kinetics of a limestone sorbent in low co 2 partial pressures using tga experiments. Energy Procedia, 114:259-270, 
2017. ISSN 18766102. doi: 10.1016/j.egypro.2017. 03.1168 .

[19] F. García-Labiano, A. Abad, L. F. de Diego, P. Gayán, and J. Adánez. Calcination of calciumbased sorbents at pressure in a broad range of co2 concentrations. Chemical Engineering Science, 57 (13):2381-2393, 2002. ISSN 00092509. doi: 10. 1016/S0009-2509(02)00137-9.

[20] J.-W. Snoeck, G. F. Froment, and M. Fowles. Steam/co 2 reforming of methane. carbon filament formation by the boudouard reaction and gasification by co 2 , by h 2 , and by steam: Kinetic study. Industrial \& Engineering Chemistry Research, 41 (17):4252-4265, 2002. ISSN 0888-5885. doi: 10. 1021/ie010666h.

[21] Calvin H. Bartholomew. Carbon deposition in steam reforming and methanation. Catalysis Reviews, 24 (1):67-112, 2007. ISSN 0161-4940. doi: 10.1080/ 03602458208079650 .

[22] K. O. Christensen, D. Chen, R. L?deng, and A. Holmen. Effect of supports and ni crystal size on carbon formation and sintering during steam methane reforming. Applied Catalysis A: General, 314(1):9-22, 2006. ISSN 0926860X. doi: 10.1016/j.apcata.2006. 07.028 .

[23] Ion Iliuta, Raul Tahoces, Gregory S. Patience, Sebastien Rifflart, and Francis Luck. Chemicallooping combustion process: Kinetics and mathematical modeling. AIChE Journal, 235:NA-NA, 2010. ISSN 00011541. doi: 10.1002/aic.11967.

[24] Min Yan, Min Zeng, Qiuyang Chen, and Qiuwang Wang. Numerical study on carbon deposition of sofc with unsteady state variation of porosity. Applied Energy, 97:754-762, 2012. ISSN 03062619. doi: 10. 1016/j.apenergy.2012.02.055.

[25] Yacine Benguerba, Lila Dehimi, Mirella Virginie, Christine Dumas, and Barbara Ernst. Modelling of methane dry reforming over ni/al2o3 catalyst in a fixed-bed catalytic reactor. Reaction Kinetics, Mechanisms and Catalysis, 114(1):109-119, 2015. ISSN 1878-5190. doi: 10.1007/s11144-014-0772-5.

[26] Yacine Benguerba, Lila Dehimi, Mirella Virginie, Christine Dumas, and Barbara Ernst. Numerical investigation of the optimal operative conditions for the dry reforming reaction in a fixed-bed reactor: Role of the carbon deposition and gasification reactions. Reaction Kinetics, Mechanisms and Catal$y$ sis, 115(2):483-497, 2015. ISSN 1878-5190. doi: 10.1007/s11144-015-0849-9.
[27] Yasukatsu Tamai, Haruo Watanabe, and Akira Tomita. Catalytic gasification of carbon with steam, carbon dioxide and hydrogen. Carbon, 15(2): 103-106, 1977. ISSN 00086223. doi: 10.1016/ 0008-6223(77)90024-0.

[28] Hazzim F. Abbas and W.M.A. Wan Daud. Hydrogen production by methane decomposition: A review. International Journal of Hydrogen Energy, 35 (3):1160-1190, 2010.

[29] Zerong Wang. Comprehensive Organic Name Reactions and Reagents. John Wiley \& Sons, Inc, Hoboken, NJ, USA, 2010.

[30] J. Carlos Abanades and Diego Alvarez. Conversion limits in the reaction of co 2 with lime. Energy \& Fuels, 17(2):308-315, 2003. ISSN 0887-0624. doi: 10.1021/ef020152a.

[31] Konstantinos Atsonios, Myrto Zeneli, Aristeidis Nikolopoulos, Nikos Nikolopoulos, Panagiotis Grammelis, and Emmanuel Kakaras. Calcium looping process simulation based on an advanced thermodynamic model combined with cfd analysis. Fuel, 153:370-381, 2015. ISSN 00162361. doi: 10.1016/j. fuel.2015.03.014.

[32] E. Lorente. Kinetic study of the redox process for separating and storing hydrogen: Oxidation stage and ageing of solid. International Journal of Hydrogen Energy, 33(2):615-626, 2008. ISSN 03603199. doi: 10.1016/j.ijhydene.2007.09.026.

[33] Marcus Wenzel, Liisa Rihko-Struckmann, and Kai Sundmacher. Thermodynamic analysis and optimization of RWGS processes for solar syngas production from $\mathrm{CO}_{2}$. AIChE Journal, 63(1):15-22, 2017.

[34] Jaakko Ylätalo, Jouni Ritvanen, Borja Arias, Tero Tynjälä, and Timo Hyppänen. 1-dimensional modelling and simulation of the calcium looping process. International Journal of Greenhouse Gas Control, 9: 130-135, 2012. ISSN 17505836. doi: 10.1016/j.ijggc. 2012.03.008.

[35] Ozgur Baskan, editor. Optimization Algorithms Methods and Applications. InTech, 2016. ISBN 978953-51-2592-1. doi: 10.5772/61426.

[36] Christoph Hertel, Peter Heidebrecht, and Kai Sundmacher. Experimental quantification and modelling of reaction zones in a cyclic watergas shift reactor. International Journal of Hydrogen Energy, 37(3): 2195-2203, 2012. ISSN 03603199. doi: 10.1016/j. ijhydene.2011.10.085. 
[37] Marcus Wenzel, Liisa Rihko-Struckmann, and Kai Sundmacher. Continuous production of co from co 2 by rwgs chemical looping in fixed and fluidized bed reactors. Chemical Engineering Journal, 336:278296, 2018. ISSN 13858947. doi: 10.1016/j.cej.2017. 12.031 .

[38] Duo Sun, Faisal Mohamed Khan, and David S.A. Simakov. Heat removal and catalyst deactivation in a sabatier reactor for chemical fixation of co 2 : Simulation-based analysis. Chemical Engineering Journal, 329:165-177, 2017. ISSN 13858947. doi: 10.1016/j.cej.2017.06.160.

[39] Marisa N. Pedernera, Juliana Piña, and Daniel O. Borio. Kinetic evaluation of carbon formation in a membrane reactor for methane reforming. Chemical Engineering Journal, 134(1-3):138-144, 2007. ISSN 13858947. doi: 10.1016/j.cej.2007.03.051.

[40] Anastasios Kambolis, Tilman J. Schildhauer, and Oliver Kröcher. Co methanation for synthetic natural gas production. Chimia, 69(10):608-613, 2015. ISSN 0009-4293. doi: 10.2533/chimia.2015.608.

[41] Jens Bremer, Karsten H. G. Rätze, and Kai Sundmacher. Co 2 methanation: Optimal start-up control of a fixed-bed reactor for power-to-gas applications. AIChE Journal, 63(1):23-31, 2017. ISSN 00011541. doi: 10.1002/aic.15496.

[42] Ammar Khawam and Douglas R. Flanagan. Solidstate kinetic models: basics and mathematical fundamentals. The journal of physical chemistry. $B$, 110(35):17315-17328, 2006. ISSN 1520-6106. doi: 10.1021/jp062746a.

[43] P. W. Atkins and Julio de Paula. Physical Chemistry. W.H. Freeman, New York, 9th ed. edition, 2010.

[44] Hong Yong Sohn. On the rate expressions for "reversible" gas-solid reactions. Metallurgical and Materials Transactions B, 45(5):1600-1602, 2014.

[45] Octave Levenspiel. Chemical Reaction Engineering. Wiley-Blackwell, New York, 3rd ed. edition, 2005. ISBN 9780471427766.

[46] Lorenz T. Biegler. Nonlinear Programming: Concepts, Algorithms, and Applications to Chemical Processes. Society for Industrial and Applied Mathematics: Mathematical Programming Society, Philadelphia, 2010.

[47] Matteo Maestri and Karsten Reuter. Molecularlevel understanding of wgs and reverse wgs reactions on rh through hierarchical multiscale approach. Chemical Engineering Science, 74:296-299,
2012. ISSN 00092509. doi: 10.1016/j.ces.2012.02. 043. 